\section{ACKNOWLEDGMENTS}

We would like to thank Spontaneous McKnight from Bio-Rad for the RiboGreen protocol adaptation used on the iCycler for cycling conditions compatible with fluorometer function. This material is based upon work supported by the Office of Research and Development, Medical Research Service, Department of Veterans Affairs, and the NIH/NIAAA.

\section{REFERENCES}

1.Bustin, S. 2000. Absolute quantification of mRNA using real-time reverse transcription polymerase chain reaction assays. J. Mol. Endocrinol. 25:169-193.

2.Orlando, C., P. Pinzani, and M. Pazzagli. 1998. Developments in quantitative PCR. Clin. Chem. Lab. Med. 36:255-269.

3.Peirson, S., J. Butler, and R. Foster. 2003. Experimental validation of novel and conventional approaches to quantitative real-time PCR data analysis. Nucleic Acids Res. 31:e73.

4.Freeman, W., S. Walker, and K. Vrana. 1999. Quantitative RT-PCR: pitfalls and potential. BioTechniques 26:112-115.

5.Jones, L., S. Yue, C. Cheung, and V. Singer. 1998. RNA quantitation by fluorescencebased solution assay: RiboGreen reagent characterization. Anal. Biochem. 265:368-374.

6.Gonzalez, J. and C. Saiz-Jimenez. 2003. Optical thermal cycler for use as a fluorimetric plate reader to estimate DNA concentrations. BioTechniques 34:710-712.

7.Kalajzic, Z., P. Liu, I. Kalajzic, Z. Du, A. Braut, M. Mina, E. Canalis, and D. Rowe. 2002. Directing the expression of a green fluorescent protein transgene in differentiated osteoblasts: comparison between rat type I collagen and rat osteocalcin promoters. Bone 31:654-660.

8.Winer, J., C. Jung, I. Shackel, and P. Williams. 1999. Development and validation of real-time quantitative reverse transcriptasepolymerase chain reaction for monitoring gene expression in cardiac myocytes in vitro. Anal. Biochem. 270:41-49.

9.Bustin, S. 2002. Quantification of mRNA using real-time reverse transcription PCR (RT-PCR): trends and problems. J. Mol. Endocrinol. 29:23-39.

Received 29 August 2003; accepted 14 October 2003.

Address correspondence to Kristine $M$. Wiren, Portland VA Medical Center, P3R\&D39, 3710 SW US Veterans Hospital Road, Portland, OR 97239, USA. e-mail: wirenk@ohsu.edu

\title{
pTOC-KR: a positive selection cloning vector based on the ParE toxin
}

\author{
Han Geun Kim ${ }^{1}$, Hyun Jin Hwang ${ }^{1}$, Min Sung Kim ${ }^{3}$, Dong Yun Lee ${ }^{1}$, Sung \\ Kyun Chung ${ }^{1}$, Jung Min Lee ${ }^{1,2}$, Ji Hyun Park ${ }^{4}$, and Dae Kyun Chung ${ }^{1,2,3}$ \\ ${ }^{1}$ Kyung Hee University, Suwon, Korea, ${ }^{2}$ RNA Inc., Suwon, Korea, ${ }^{3}$ DNA Inc., \\ Seoul, Korea, and ${ }^{4}$ University College London, London, UK
}

BioTechniques 36:60-64 (January 2004)

Several prokaryotic cloning vectors have been developed to clone foreign DNA in bacteria. The insertion inactivation of $\beta$-galactosidase activity, for instance, is a common screening method of identifying recombinant DNA molecules in many vectors $(1,2)$. However, this system poses several problems. For one, many vectors can self-ligate and give false transformants. Although $\beta$-galactosidase is widely used as a screening marker, it is limited to use with specially mutated Escherichia coli hosts for $\alpha$-complementation. The color of the colonies is also hard to distinguish when the blue/white selection system is used. This system also requires expensive reagents: 5-bromo4-chloro-3-indolyl- $\beta$-D-galactosidase (X-Gal) and isopropylthio- $\beta$-D-thiogalactopyranoside (IPTG).

To address these problems, several positive selection vector systems have been developed based on the toxinantitoxin systems parD (Kis/Kid) of plasmid R1 (3) and on the CcdAB system of plasmid F (4). Similar positive selection cloning vectors using the transcriptional factor GATA-1 (5) or a cellulase gene $(\mathrm{CelA})$ as screening marker (6) have also been developed. Nonetheless, the application of these systems is also limited; in most cases, they are host-limited and their cloning

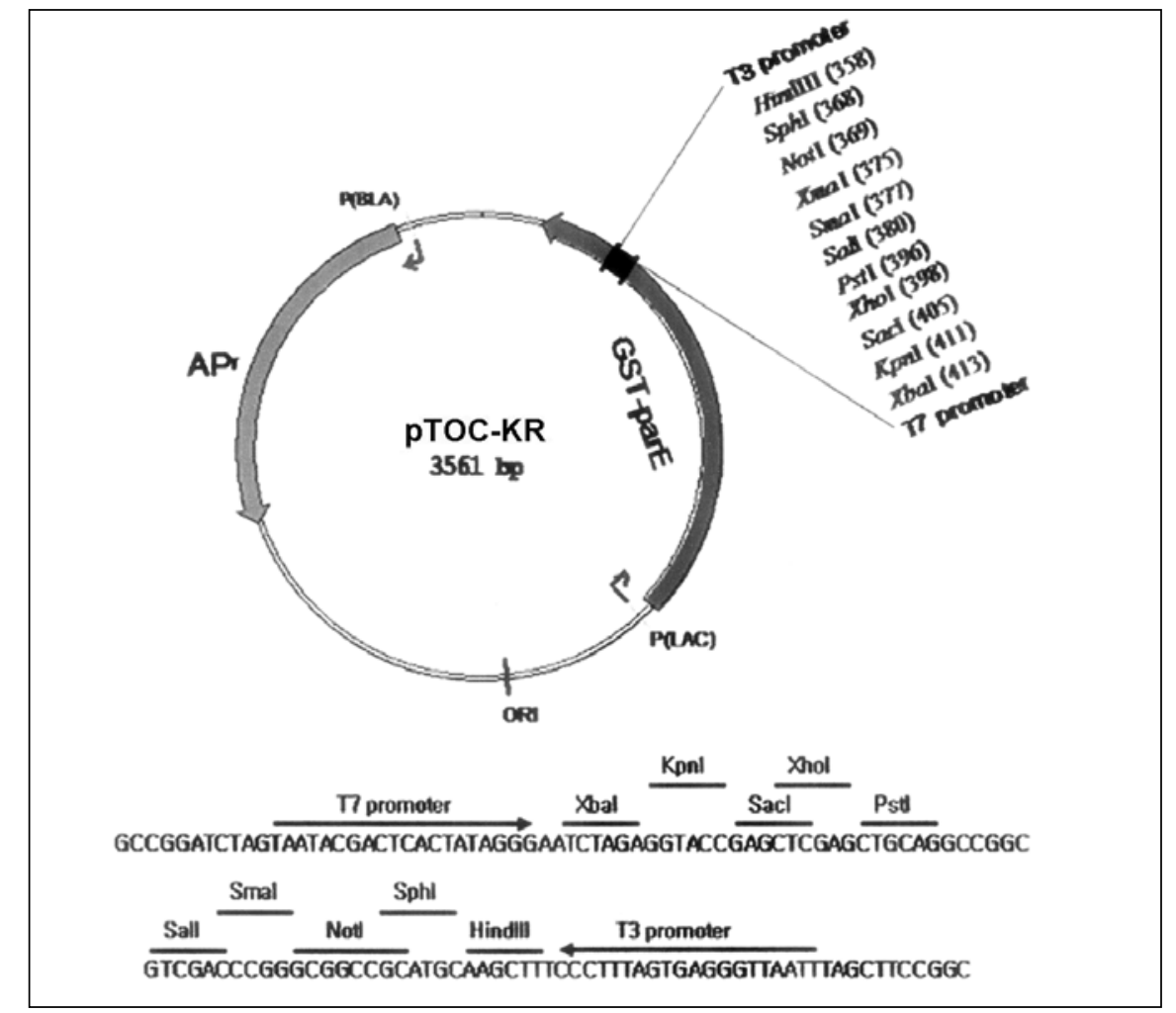

Figure 1. Map of pTOC-KR. The main feature of the vector is shown. Various multiple cloning sites and $\mathrm{T} 7 / \mathrm{T} 3$ promoter sequences of the vector are represented. 
efficiencies are not satisfactory.

This study developed a very efficient positive selection cloning vector based on the parE toxin gene derived from the parDE operon of the Escherichia coli plasmid RK2 $(7,8)$. As the ccdAB system of plasmid $\mathrm{F}$, the growth inhibition of ParE is induced by a postsegregational killing system (4). This system usually involves two proteins: one acts as a toxin, and the other as an antitoxin $(7,9)$. By binding to the A subunit of DNA gyrase and restraining its activity (10), 12-kDa ParE inhibits the early stages of both chromosomal and plasmid DNA replication in E. coli. On the other hand, 9-kDa ParD binds to ParE to prevent its inhibitory activities and functions as an antitoxin $(7,9,11)$.

To create multiple cloning sites (MCSs) in the internal region of the toxin gene, a stable region in the glutathioneS-transferase (GST)-parE gene was located through oligonucleotide insertion. Though several regions of the GST-parE gene such as DdeI, EspI, AvaII, NgoMIV, and $B c l I$ were used in this study, the NgoMIV site of the parE gene was only suitable for making MCSs. When a 36-mer synthetic oligonucleotide (with an unaltered open reading frame) was inserted into this region, ParE toxicity was still triggered. Likewise, E. coli containing this recombinant plasmid did not grow (data not shown). Nonetheless, other sites including DdeI, EspI, AvaII, and $B c l I$ were rendered unsuitable due to ParE destruction. The maximum length of insert was determined to avoid toxin deactivation through MCS insertion. The size was 144 bp (data not shown), suggesting that longer insertions of cloning genes disrupt the ParE toxin effect.

A 3.56-kb positive selection cloning vector (pTOC-KR) was manufactured based on the parE toxin gene. The MCS of pTOC-KR contained various

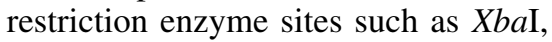
KpnI, SacI, XhoI, PstI, SalI, SmaI, NotI, SphI, and HindII (Figure 1). T7 and T3 primer sequences were also included in the adjacent sites of the MCS. Digestion with restriction enzymes having specific corresponding sites within the MCS and DNA sequencing analysis confirmed the inserted MCS and $\mathrm{T} 7 / \mathrm{T} 3$ primer sequences.

A serial toxin test was performed with the constructed pTOC-KR to examine the positive growth selection system. pTOC-KR was transformed into E. coli XL1-Blue (Stratagene, La Jolla, CA, USA) with pRR46 plasmid, and several thousands of colonies were obtained from the LB-ampicillin + kanamycin plates (data not shown). From a colony of these transformants, pTOC-KR was purified and transformed back into $E$. coli XL1-blue. In the back transformation experiment, however, colonies did not grow well in ampicillin plates; only 2-3 colonies were observed per plate. The same results were obtained when these experiments were performed using other E. coli strains such as BL21, DH5 $\alpha$, JM109, and JM110 (data not

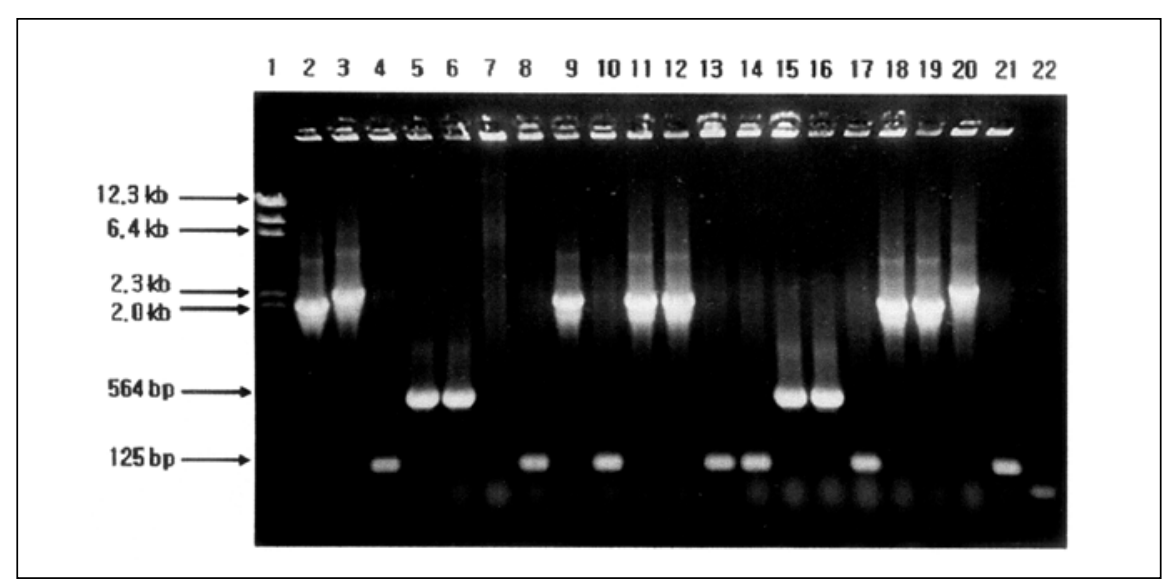

Figure 2. Cloning of $\lambda$ DNA fragments by pTOC-KR. Fifty cloning samples were amplified to check for the presence of insert with PCR, and 20 samples are shown in this figure. Lane 1 is the $\lambda / H$ indIII marker; lane $2,11,12,18$, and 19 are 2.0-kb $\lambda$ DNA fragments; lane 3, 9, and 20 are 2.4-kb $\lambda$ DNA fragments; lane 5, 6, 15, and 16 are 564-bp $\lambda$ DNA fragments; lane 4, 8, 10, 13, 14, 17, and 21 are 125-bp $\lambda$ DNA fragments; lane 22 is a negative control: only the multiple cloning site (MCS) region was amplified by $\mathrm{T} 7$ and $\mathrm{T} 3$ primer, and lane 7 did not contain any of the $\lambda$ DNA fragments. shown). These results indicated that cell growth was still inhibited by ParE toxin activity. Such function is applicable to many other E. coli hosts because ParE toxin activity can function in various types of E. coli $(12,13)$.

To test the cloning efficiency of pTOC-KR, various sizes of $\lambda /$ HindIIIdigested DNA fragments were cloned. Out of the randomly selected 50 colonies, 46 colonies contained one of the $\lambda$ DNA fragments. Likewise, 4 out of $8 \lambda$ DNA fragments in these 46 clones were represented (Figure 2). No colony with a fragment longer than $4.3 \mathrm{~kb}$ was detected. The inability to clone large fragments of $\lambda$ DNA might not reflect a constraint on the DNA fragment size, but it might suggest the expression of phage genes from the vector.

In another test, HindIII-digested 1-kb DNA fragments were cloned into a unique HindIII site located in pTOC-KR. The fragments were then ligated with the different ratios of vector to insert at 1:1, 3:1, 10:1, and 100: 1. The following day, the proportion of colonies growing on the plates was greatly increased. Even when the ratio of vector to insert was 100:1, a large number of colonies grew on the plates (data not shown).

From each test, 50 colonies were randomly selected and subsequently amplified with the colony PCR to test for the presence of inserted fragments. About 48-49 colonies per sample group contained foreign DNA fragments. In addition, the restriction enzyme analysis revealed that all PCRdetected colonies contained the insert. These tests were performed several times, with at least $96 \%$ of the colonies always having desirable inserts despite the varying ratios of vector to insert to produce various numbers of colonies.

In conclusion, we have developed a positive cloning vector (pTOC-KR) based on the parE toxin gene. When pTOC-KR was transformed into $E$. coli without a foreign insert DNA, GSTParE encoded from pTOC-KR completely prevented cell growth. When an insert DNA was cloned into the GSTParE region of pTOC-KR, however, several thousands of transformants were obtained and at least $96 \%$ of all transformants had inserts. Moreover, dephosphorylation of pTOC-KR to 
avoid self-ligation is not required, and transformants could be easily isolated without using X-Gal and IPTG. In addition, pTOC-KR had excellent cloning efficiency in various types of $E$. coli strains, such as E. coli XL1-blue, BL21, DH5 $\alpha$, JM109, and JM110, and showed its potential broad host-range character in other types of $E$. coli.

\section{ACKNOWLEDGMENTS}

We wish to express our appreciation to Dr. D.R. Helinski, who kindly provided pAS12 and pRR46. This work was supported by Kyung Hee University, Korea.

\section{REFERENCES}

1.Yanisch-Perron, C., J. Vieira, and J. Messing. 1985. Improved M13 phage cloning vectors and host strains: nucleotide sequences of the M13 and pUC19 vectors. Gene 33:103-119.

2.Marsh, J.L., E. Marry, and J.W. Evan. 1984. The pIc plasmid and phage vectors with versatile cloning sites for recombinant screening by insertional inactivation. Gene 32:481-485.

3.Gabant P, T. Van Reeth, P.L. Dreze, M. Faelen, C. Szpirer, and J. Szpirer. 2000. New positive selection system based on the parD (kis/kid) system of the R1 plasmid. BioTechniques 28:784-788.

4.Bernard, P. 1995. New ccdB positive-selection cloning vectors with kanamycin or chloramphenicol selectable markers. Gene 162: 159-160.

5.Trudel, P., S. Provost, B. Massie, P. Chartrand, and L. Wall. 1996. pGATA: A positive selection vector based on the toxicity of the transcription factor GATA-1 to bacteria. BioTechniques 20:684-693.

6.Jang, S.J., W.J. Park, S.K. Chung, C.Y. Jeong, and D.K. Chung. 2001. New E.coli cloning vector using a celluase gene (celA) as a screening marker. BioTechniques 31: 1064-1068.

7.Hohnson, E.P., A.R. Strom, and D.R. Helinski. 1996. Plasmid RK2 Toxin protein ParE: Purification and Interaction with the ParD Antitoxin protein. J. Bacteriol. 178:1420-1429.

8.Roberts, R.C. and D.R. Helinski. 1993. Characteristics and significance of DNA binding activity of plasmid stabilization protein ParD from the broad-host-range plasmid RK2. J. Biol. Chem. 268:27109-27117.

9.Jovanovic, O.S., E.K. Ayres, and D.H. Figurski. 1994. Host-inhibitory functions encoded by promiscuous plasmids: transient arrest of Escherichia coli segregants that fail to inherit plasmid RK2. J. Mol. Biol. 237:52-64.

10.Jian, Y., J. Pogliano, D.R. Helinski, and I. Konieczny. 2002. ParE toxin encoded by the broad-host-range plasmid RK2 is an inhibitor of Escherichia coli gyrase. Mol. Microbiol. 44: 971-979.
11.Roberts, R.C., A.R. Strom, and D.R. Helinski. 1994. The parDE operon of the broad-hostrange plasmid RK2 is an inhibition associated with plasmid loss. J. Mol. Biol. 237:35-51.

12.Greener, A., S.M. Lehman, and D.R. Helinski. 1992. Promoters of the broad host range plasmid RK2: analysis of transcription (initiation) in five species of gram-negative bacteria. Genetics 130:27-36.

13.Thomas, C.M. and D.R. Helinski. 1989. Vegetative replication and stable inheritance of IncP plasmids, p. 1-25. In C.M. Thomas (Eds.), Promiscuous Plasmids of Gram-Negative Bacteria. Academic Press, San Diego.
Received 5 September 2003; accepted 3 November 2003.

Address correspondence to Dae Kyun Chung, School of Biotechnology and Institute of Life Science and Resources, 308 College of Industrial Microbiology, Kyung Hee University, Suwon, Korea. e-mail: dkchung@khu.ac.kr

\title{
Cost-benefit analysis of a method using diatomaceous earth to purify Tamm-Horsfall protein
}

\author{
Jaideep Shenoi ${ }^{1}$, Biji T. Kurien ${ }^{2}$, Sadamu Kurono ${ }^{3}$, Ranjan Mascarenhas ${ }^{3}$, \\ Hiroyuki Matsumoto $^{3}$, and Robert H. Scofield ${ }^{2,3}$ \\ ${ }^{1}$ University of Oklahoma Health Sciences Center, Tulsa, ${ }^{2}$ Oklahoma Medical Research \\ Foundation, Oklahoma City, and ${ }^{3}$ University of Oklahoma Health Sciences Center, \\ Oklahoma City, OK, USA
}

BioTechniques 36:64-66 (January 2004)

Ever since Tamm and Horsfall first identified Tamm-Horsfall protein (THP) over a half-century before, its true function has baffled investigators (1). Studies have suggested that THP could have a role in prevention of urinary tract infection (UTI) by its adherence properties $(2,3)$. THP is synthesized in the thick ascending kidney tubules and is not found anywhere else in the body, although the THP gene is evolutionarily conserved in all vertebrates (4). THP exists as a polymeric glycoprotein with a monomeric molecular weight (MW) of 88,000 , and storage of THP has always proven to be difficult. THP quantitatively decreases over time even when dissolved in phosphate buffer at $4^{\circ} \mathrm{C}$. This phenomenon was prevented when using Triton ${ }^{\circledR} \mathrm{X}-100$ and EDTA at an alkaline pH (TEA) instead of phosphate buffer (5).

The cost of commercial THP is $\$ 155 / 100 \mu \mathrm{g}$ (Biomedical Technologies, Stoughton, MA, USA). Currently, THP can be purified using two different published methods. The original method described by Tamm and Horsfall (1950) is time-consuming (1). The second method, by Serafini-Cessi et al. (6), uses diatomaceous earth and then utilizes deionized water for the desorption of THP. This results in a reduced time of 4-6 h to purify the same amount of THP from urine, excluding dialysis and lyophilization.

Our aim was to utilize inexpensive and freely available materials to develop an uncomplicated and reproducible procedure with a shorter time frame. Molecular weight markers were obtained from Invitrogen (Carlsbad, CA, USA). The sodium dodecyl sulfate (SDS)-polyacrylamide precast gel (12\%) was obtained from ISC BioExpress (Kaysville, UT, USA), and the filtering agent Celite ${ }^{\circledR} 521$ and the diatomaceous earth (DE) were both from Sigma (St. Louis, MO, USA). DE was also obtained from Best Prices Storable Foods (Dallas, TX, USA). All other reagents were of analytical grade.

THP was purified using the most recent and quick method available (6).

Large volumes of $1.5 \mathrm{~L}$ of overnight urine were collected and neutralized with $10 \mathrm{M} \mathrm{NaOH}$. It was then filtered through $20 \mathrm{~g}$ of DE layered on a Whatman no. 1 